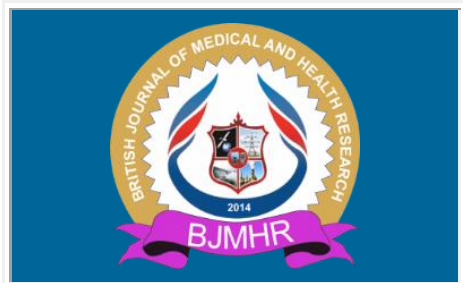

\title{
BJMHR
}

British Journal of Medical and Health Research

Journal home page: www.bjmhr.com

\section{Isolation and Characterization of Secondary Metabolites And Evaluation of Biological Activity of Hygrophila erecta (Burm.f.) Hochr.}

\section{Faria Mannan Mithi ${ }^{1 *}$, Monira Ahsan', Choudhury Mahmood Hasan', A.T.M Zafrul Azam ${ }^{1}$ \\ 1.Department of Pharmaceutical Chemistry, Faculty of Pharmacy, University of Dhaka, Dhaka-1000, Bangladesh.}

\begin{abstract}
Hygrophila erecta (Burm.f.) Hochr. belonging to the Acanthaceae family, is a moisture loving genera and a perennial herb whose seeds are used as a skin-regenerating product. The concentrated ethyl acetate soluble fraction of methanolic extract of this whole plant resulted in a mixture of 4-methoxybenzoic acid and 4-methoxycinnamic acid, another mixture of two ester derivatives: methyl linoleate and methyl stearate, lupeol, $\beta$-Sitosterol and Stigmasterol. The crude methanolic extract of the whole plant was partitioned to petroleum ether soluble fraction, chloroform soluble fraction, ethyl acetate soluble fraction and aqueous soluble fraction for the purpose of investigations of different biological activities. The ethyl acetate soluble fraction expressed the highest antioxidant property in DPPH free radical scavanging method, whilst the different extractives exhibited moderate to strong cytotoxicity in brine shrimp lethality test and the highest activity was shown by pet ether soluble fraction. Furthermore, the pet ether soluble fraction also demonstrated highest thrombolytic activity compared to the standard streptokinase, while the other fractions showed moderate to lower activity. However, no antimicrobial activity was observed for any of the fractions investigated using standard tetracycline and ciprofloxacin. The methanolic extract further produced statistically significant peripheral analgesic and antidiarrheal activity at both $200 \mathrm{mg} / \mathrm{kg}$ and $400 \mathrm{mg} / \mathrm{kg}$ doses. Although, it expressed blood glucose lowering activity, but it was not statistically significant.
\end{abstract} Keywords: Hygrophila erecta (Burm.f.) Hochr., Acanthaceae, Methyl linoleate and methyl stearate, 4-methoxybenzoic acid and 4-methoxycinnamic acid, Antioxidant, Cytotoxicity. 


\section{INTRODUCTION}

\section{Preliminary considerations}

Traditionally medicinal plants have been used in the preparation of synthetic medicines, even currently in developing world; about $25 \%$ of ingredients in the prescribed modern medicine are derived from extracts of medicinal plant ${ }^{1}$. Acanthaceae is a large family of dicotyledonous flowering plants including about 4300 species and 346 genera all over the world. Family Acanthaceae is a large family of herbs, shrubs or twining vines and some are epiphytes of flowering plants and made it among the top 12 most diverse families of flowering plants in all over the world. It is composed of mainly annual and perennial erect, prostrate or rarely climbing, herbs, shrubs, under shrubs, perennial climbers and rarely small trees. However, it also includes some large trees ${ }^{2}$. This family contributes to diverse secondary metabolites, such as alkaloids, phenols, antraquinones, benzamides, coumarin, terpenoids, tannins, flavonones, cardiac glycosides, saponins, carbohydrates, flavonoids and proteins that have many therapeutic uses. Its native range is Indian Subcontinent to China (Yunnan, Guangdong) and Philippines ${ }^{3}$.

Hygrophila erecta (Burm.f.) Hochr. in Acanthaceae family was collected from Jahangirnagar, Savar, Bangladesh in March 2018 an identified at the Bangladesh National Herbarium by an expert taxonomist (accession no: DACB 46002).

\section{MATERIALS AND METHOD}

\section{General experimental procedures}

TLC aluminum plates $(20 \times 20 \mathrm{~cm})$ pre-coated with silica gel $60 \mathrm{~F} 254$ were used for qualitative work, also preparative TLC was conducted on Silica gel 60 PF254 (0.5 mm thickness, Merck) coated glass plates and vanillin $\mathrm{H}_{2} \mathrm{SO}_{4}$ spray reagent were used for purification and detection purpose. Sephadex LH-20 was used to perform gel permeation chromatography. Proton Magnetic Resonance ( ${ }^{1} \mathrm{H}$ NMR) was recorded on Brucker (400 MHZ) instrument. The spectra were obtained using deuterated solvent $\left(\mathrm{CDCl}_{3}\right)$.

\section{Extraction and isolation of the plant material}

The collected whole plant (1026.8g of powdered plant materials) of Hygrophila erecta (Burm.f.) Hochr. was soaked in a bottomed flask (5 liters) with 3.5 liters of methanol by cotton plug and aluminum foil and was kept for a period of one month with occasional shaking and stirring. Then the whole mixture was filtered with cotton and volume of filtrate was reduced using a Buchii Rotary Evaporator at low temperature $\left(40^{\circ} \mathrm{C}\right)$ and pressure. After that the filtrate was kept for drying to become dry crude extract. After proper drying, the crude extract was dissolved in distilled ethyl acetate and the ethyl acetate fraction was separated by taking the supernatant portion of the mixture. This was done for several times to have the proper amount 
of ethyl acetate fraction of crude extract. Meanwhile, the final dried ethyl acetate soluble fraction of crude extract was $19.6 \mathrm{~g}$, which was then subjected to VLC on silica gel $60 \mathrm{H}$, whilst developed 35 VLC fractions due to increasing the solvent system (non-polar to polar) from hexane to methanol. Upon TLC nature, these VLC fractions again allowed for gel permeation chromatography and preparative TLC for final extraction of the detected compounds.

\section{Compound 1 (HE-167)}

Compound 1 (HE-167) was isolated as colorless crystals from VLC fraction 16-18, which further undergone gel permeation chromatography with Sephadex LH-20 followed by preparative TLC using ethyl acetate: toluene $=20: 80$ solvent systems. It also expressed quenching spot on TLC plate upon UV visualization $(254 \mathrm{~nm})$, but no color upon spraying vanillin sulphate and heating. The ${ }^{1} \mathrm{H}$ NMR $\left(400 \mathrm{MHz}, \mathrm{CDCl}_{3}\right)$ data of compound 1 represents $\delta 7.98(2 \mathrm{H}, \mathrm{d}, J=8.8 \mathrm{~Hz}, \mathrm{H}-2,6), \delta 6.87(2 \mathrm{H}, \mathrm{d}, J=8.8 \mathrm{~Hz}, \mathrm{H}-3,5), \delta 7.46(2 \mathrm{H}, \mathrm{d}, J=8.8 \mathrm{~Hz}, \mathrm{H}-$ 2,6), $\delta 6.87(2 \mathrm{H}, \mathrm{d}, J=8.8 \mathrm{~Hz}, \mathrm{H}-3,5), \delta 7.66(1 \mathrm{H}, \mathrm{d}, J=16 \mathrm{~Hz}, \mathrm{H}-7), \delta 6.33(1 \mathrm{H}, \mathrm{d}, J=16 \mathrm{~Hz}$, $\mathrm{H}-8), \delta 3.91$ (3H, s, OMe-4) and $83.82(3 \mathrm{H}, \mathrm{s}, \mathrm{OMe}-4)$.

\section{Compound 2 (HE-57)}

Compound 2 (HE-57) was derived from VLC fraction 5, whilst purified by preparative TLC using toluene: hexane=30: 70 as solvent systems and quenching spot upon UV visualization (254 nm) and no color upon spraying vanillin sulphate, but turns black upon heating at $110{ }^{\circ} \mathrm{C}$ for 2 mins. The ${ }^{1} \mathrm{H}$ NMR (400 MHz, $\mathrm{CDCl}_{3}$ ) data of compound 2 expressed $\delta 2.31(\mathrm{t}, J=6.6$ Hz, H-2), $\delta 1.61$ (m, H-3), $\delta 1.25-1.30$ (8H, m, H-4 to H-7), $\delta 1.25-1.30$ (28m, H-4 to H-17), $\delta 2.03$ (m, H-8), $\delta 5.35$ (4H, m, H-9,10,12,13), $\delta 2.78$ (m, H-11), $\delta 2.03$ (m, H-14), $\delta 1.25-1.30$ $(6 \mathrm{H}, \mathrm{m}, \mathrm{H}-15,16,17), \delta 0.89$ (m, H-18), $\delta 3.66$ (3H, s, O-CH3-18).

\section{Compound 3 (HE-100)}

Compound 3 (HE-100) was collected from VLC 10-11 and further gel permeation chromatography fraction 19 as pure colorless crystals. It was not observed on UV visualization (254 $\mathrm{nm}$ ), but upon spraying with vanillin sulphate it expressed purple color and turns black upon heating at $110^{\circ} \mathrm{C}$ for 2 mins.

The ${ }^{1} \mathrm{H}$ NMR (400 MHz, $\mathrm{CDCl}_{3}$ ) data of compound 3 showed $\delta 3.20$ (dd, J=11.2 Hz,4.8 Hz, H-3), $\delta 2.39$ (m, H-19), $\delta 0.98$ (3H, s, H-23), $\delta 0.85$ (3H, s, H-24), $\delta 1.05$ (3H, s, H-25), $\delta 0.81$ $(3 \mathrm{H}, \mathrm{s}, \mathrm{H}-26), \delta 0.78$ (3H, s, H-27), $\delta 0.99$ (3H, s, H-28), $\delta 4.65$ (br. s, H-29), $\delta 4.65$ (br. s, H-29), $\delta 1.70(3 \mathrm{H}, \mathrm{s}, \mathrm{H}-30)$.

\section{Compound 4 (HE-130)}

Compound 4 (HE-130) was obtained as a pure colorless needle like crystals from VLC fraction 13, which had no quenching spot upon UV visualization $(254 \mathrm{~nm})$ on TLC plate and no color upon spraying vanillin sulphate, but turns dark brown upon heating at $110{ }^{\circ} \mathrm{C}$ for 2 mins. The ${ }^{1} \mathrm{H}$ NMR (400 MHz, $\mathrm{CDCl}_{3}$ ) data of compound 4 expressed $\delta 3.55$ (m, H-3), $\delta 5.37$ (d, J=5.2 
Hz, H-6), $\delta 0.72$ (s, H-18), $\delta 1.03$ (s, H-19), $\delta 0.94$ (d, J=6.4 Hz, H-21), $\delta 5.04$ (1H, dd, J=15.2

Hz, 8.4 Hz, H-22), $\delta 5.18$ (1H, dd, J=15.2 Hz, 8.8 Hz, H-23), $\delta 0.82$ (d, J=6.8 Hz, H-26), $\delta 0.87$ (d, $J=6 \mathrm{~Hz}, \mathrm{H}-27)$ and $\delta 0.85$ (t, $J=7.5 \mathrm{~Hz}, \mathrm{H}-29)$.

\section{Biological design}

The crude extract $(5 \mathrm{gm})$ was used for the preparation of sample for biological investigation. Here, a protocol was followed, designed by Kupchan and modified by VanWanenen ${ }^{4}$. The sample was dissolved in $10 \%$ aqueous methanol solution and then extracted with petroleum ether, chloroform, ethyl acetate and finally with water by using separating funnel.

For In-vivo test, swiss albino mice (weighing 15-25g) were obtained from the animal house, Jahangirnagar, Bangladesh. All animal sample were housed in proper cages with adequate lighting and ventilation. All experimental studies were conducted following the ethical guidelines of laboratory animal care and appropriate permissions obtained from the relevant authorities of the State University of Bangladesh prior to commencing the experiments.

\section{Antioxidant activity}

The antioxidant activity was assessed by using DPPH method developed by Brand-Williams et $a l^{5}$. Here the antioxidant potential was evaluated from the bleaching of purple colored methanol solution of DPPH radical by the plant extract as compared to that of Butylated Hydroxyl Toluene (BHT) by UV spectrophotometer.

\section{Brine shrimp lethality bioassay}

In order to determine the cytotoxic activity of the sample, a method was selected described by Meyer et al with slight modification ${ }^{6}$ and vincristine sulphate was used here as the positive control.

\section{Thrombolytic activity}

To study the clot lysis activity of the sample, Prasad et al method was followed ${ }^{7}$. Standard streptokinase $(100 \mu \mathrm{L})$ was used as positive control and water as negative control. Aliquots (5 $\mathrm{ml}$ ) of venous blood was drawn from healthy volunteers without a history of anticoagulant therapy and oral contraceptives.

\section{Antimicrobial screening}

A standard disc diffusion method was used for the evaluation of antimicrobial activity, proposed by Bayer et al. ${ }^{8}$. Standard antibiotic (ciprofloxacin and tetracycline) discs and blank discs were used as positive and negative control against two gram positive (Staphylococcus aureus, Bacillus subtilis) and five gram negative (Shigella flexneri, Salmonella typhi, Escherichia coli, Vibrio cholera, Pseudomonus aeruginosa) bacteria. All of the sample were subjected to antimicrobial screening with a concentration of $400 \mu \mathrm{g} / \mathrm{disc}$. The antimicrobial potency of the test samples was than assessed by measuring the zone of inhibition.

\section{Evaluation of analgesic activity}


Peripheral analgesic activity was evaluated by acetic acid induced writhing method designed by Whittle ${ }^{9}$. As a standard drug, diclofenac sodium was used. The crude methanolic extracts of the sample were introduced to analgesic testing at two different doses: $200 \mathrm{mg} / \mathrm{kg}$ and 400 $\mathrm{mg} / \mathrm{kg}$ of body weight of experimental animal (mouse). The writhing count for each mouse was recorded and the average count for each group was calculated. The percentage inhibition of writhing was calculated with respect to the control.

\section{Evaluation of antidiarrheal activity}

The anti-diarrheal activity of the methanolic extract of Hygrophila erecta (Burm.f.) Hochr. was evaluated using both $200 \mathrm{mg} / \mathrm{kg}$ and $400 \mathrm{mg} / \mathrm{kg}$ doses in mice developed by Shoba et al ${ }^{10}$. In this method, each mouse was fed with $1 \mathrm{ml}$ of highly pure analytical grade of castor oil which would induce diarrhea. The numbers of fecal stools were recorded for each individual mouse. The observations of the experimental groups were compared against that of the control to evaluate the anti-diarrheal activity of the samples.

\section{Evaluation of hypoglycemic activity}

The methanolic extract of sample was investigated for the evaluation of oral hypoglycemic activity with slight modifications of method as described earlier by Joy et al ${ }^{11}$. Both $200 \mathrm{mg} / \mathrm{kg}$ and $400 \mathrm{mg} / \mathrm{kg}$ doses were examined and Glibenclamide was used as standard.

\section{RESULTS AND DISCUSSION}

\section{Chemical investigation of Hygrophila erecta (Burm.f.) Hochr.}

The successful chromatographic analysis and purification yielded four compounds and the elucidated structures revealed as 4-methoxybenzoic acid and 4-methoxycinnamic acid (HE167), methyl linoleate and methyl stearate (HE-57), Lupeol (HE-100), $\beta$-Sytosterol and Stigmasterol (HE-130) respectively.

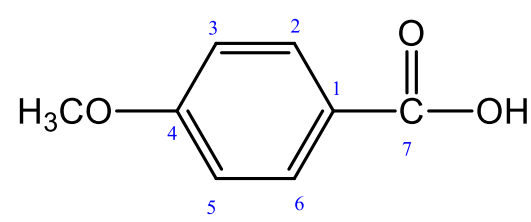

4-methoxybenzoic acid, HE-167(A)

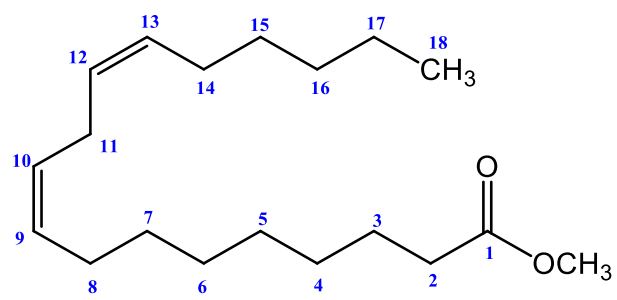

Methyl linoleiate (HE-57a)<smiles>COc1ccc(/C=C/C(=O)O)cc1</smiles>

4-methoxycinnamic acid, HE-167(B)

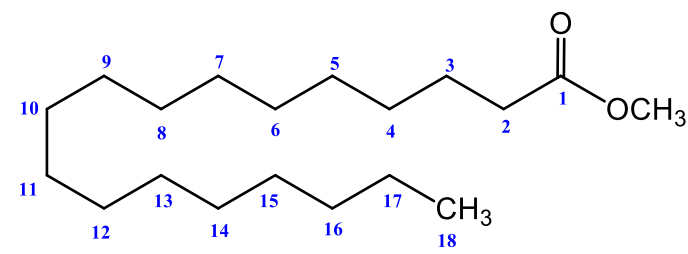

Methyl stearate (HE-57b) 


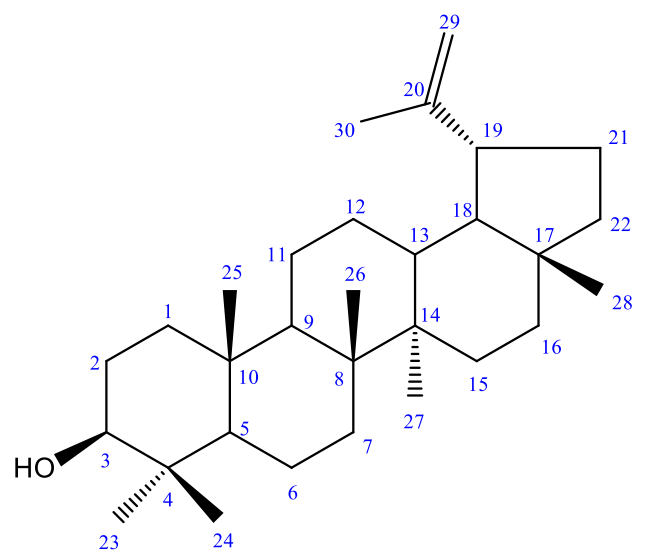<smiles>CC[C@H](CC[C@@H](C)[C@H]1CC[C@@H]2[C@]1(C)CC[C@@]1(C)[C@@]3(C)CC[C@H](O)CC3=CC[C@]21C)C(C)C</smiles>

Lupeol, HE-100

$\beta$-Sitosterol, HE-130 (A)

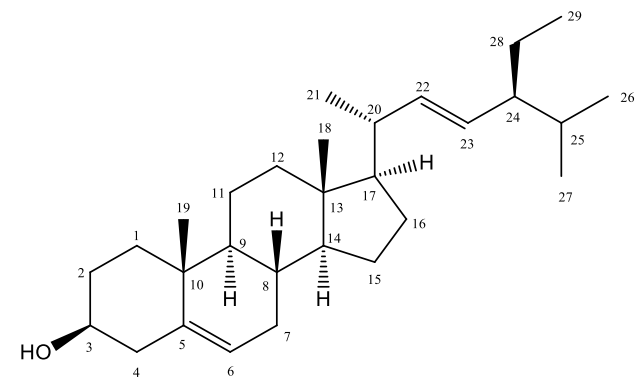

Stigmasterol, HE-130 (B)

\section{4-methoxybenzoic acid and 4-methoxycinnamic acid:}

The ${ }^{1} \mathrm{H}$ NMR spectral data of compound 1, HE-167 (A) indicated the presence of two doublets (2H each) at $\delta 7.98$ and 6.87 are assignable to aromatic protons $\mathrm{H}-2,6$ and $\mathrm{H}-3,5$; a singlet at $\delta$ 3.9 represents the presence of methoxy group at position-4. This NMR data are closely in agreement with those reported for 4-methoxybenzoic acid ${ }^{12}$. Again, ${ }^{1} \mathrm{H}$ NMR spectral data of HE-167 (B) indicated two doublets $(1 \mathrm{H}$ each) at $\delta 7.66,6.33$ are evident of the presence of trans-coupled protons $\mathrm{H}-7$ and $\mathrm{H}-8$ repectively of the cinnamoyl moiety. The two doublets $(2 \mathrm{H}$ each) at $\delta 7.98$ and 6.87 corresponding to aromatic protons $\mathrm{H}-2,6$ and $\mathrm{H}-3,5$; which are in close agreement to those observed for 4-methoxycinnamic acid ${ }^{13}$. So, the identity of this compound confirmed as a mixture of 4-methoxybenzoic acid and 4-methoxycinnamic acid. The compound has been isolated for the first time from this plant.

\section{Methyl linoleate and methyl stearate:}

The ${ }^{1} \mathrm{H}$ NMR spectrum of compound 2 (HE-57a) revealed the presence of eight proton multiplet at $\delta 1.25$ to 1.30 , the position and multiplicity indicative to 4-7 respectively. The presence of four olefinic protons at $\delta 5.35$ are assigned to position 9, 10 and 12, 13 and two multiplets at $\delta 2.78$ and 2.03 respectively. Whilst, it (HE-57b) also expressed one methylene triplet at $\delta 2.31$ and one methylene multiplet at $\delta 1.61$ in position 2 and 3 respectively. It also revealed the presence of multiplets at 4-17 with $\delta 1.25$ to 1.30 . These features indicated that it 
would be a mixture of methyl linoleate and methyl stearate by compared with the compound that was reported earlier ${ }^{14}$. This was found to be first time reported against this plant.

\section{Lupeol}

Compound 3 (HE-100) was obtained as colorless crystals and its identity ensured as lupeol by comparing the proton NMR data with those reported earlier for it ${ }^{15}$. This compound has been evaluated for the first time from this plant.

\section{$\beta-S i t o s t e r o l$ and Stigmasterol:}

Compound 4 (HE-130) was obtained as a colorless needle like crystals. Its structure confirmed as a mixture of $\beta$-Sitosterol and Stigmasterol by comparing the ${ }^{1} \mathrm{H}$ NMR features of HE-130 with those that was reported for the compound in Pateh et al ${ }^{16}$. This compound has been found to be first time reported from this plant.

\section{Antioxidant activity:}

Different organic fractions of methanolic crude extract of Hygrophila erecta (Burm.f.) Hochr. were subjected to free radical scavenging activity by the method of Brand et al. The activities of all fractions were evaluated in comparison with standard BHT, which has the $\mathrm{IC}_{50}$ value 9.64 $\mu \mathrm{g} / \mathrm{ml}$. In this investigation, ethyl acetate soluble fraction showed significant free radical scavenging activity with $\mathrm{IC}_{50}$ value $13.58 \mu \mathrm{g} / \mathrm{ml}$ (Table 1).

Table 1: IC50 values of the standard and test samples of Hygrophila erecta (Burm.f.) Hochr.

\begin{tabular}{ll}
\hline Test sample & $\mathbf{I C}_{\mathbf{5 0}}(\boldsymbol{\mu g} / \mathbf{m l})$ \\
\hline Aqueous soluble fraction & $27.76 \pm 0.17$ \\
Ethyl acetate soluble fraction & $13.58 \pm 0.09$ \\
Chloroform soluble fraction & $15.45 \pm 0.08$ \\
Pet ether soluble fraction & $414.27 \pm 0.29$ \\
Standard tert-butyl-1-hydroxytoluene (BHT) & $9.64 \pm 0.07$ \\
\hline
\end{tabular}

The data are displayed with mean \pm S.E.M.

\section{Brine shrimp lethality bioassay:}

In this investigation, pet ether soluble fraction $(5.44 \mu \mathrm{g} / \mathrm{ml})$ and aqueous fraction $(7.70 \mu \mathrm{g} / \mathrm{ml})$ expressed good cytotoxic activity compared to positive control, vincristine sulphate $(0.45$ $\mu \mathrm{g} / \mathrm{ml})$ (Table 2).

Table 2: $\mathrm{LC}_{50}$ values of test samples and standard

\begin{tabular}{ll}
\hline Test sample & $\mathbf{L C}_{\mathbf{5 0}}(\boldsymbol{\mu g} \mathbf{g} \mathbf{m l})$ \\
\hline Aqueous soluble fraction & $7.7038 \pm 0.19$ \\
Ethyl acetate soluble fraction & $15.1786 \pm 11$ \\
Chloroform soluble fraction & $41.5058 \pm 1.16$ \\
Pet ether soluble fraction & $5.4412 \pm 0.12$ \\
Vincristine Sulphate & $0.4510 \pm 0.03$ \\
\hline
\end{tabular}

The data are displayed with mean \pm S.E.M. 


\section{Thrombolytic activity:}

In this study, the pet ether soluble fraction of methanolic extract of Hygrophila erecta (Burm.f.) Hochr. exhibited highest thrombolytic activity (14.40\%). The aqueous soluble fraction and chloroform soluble fraction showed moderate thrombolytic activity while ethyl acetate soluble fraction has the lowest thrombolytic activity (Table 3).

Table 3: Thrombolytic activity (\% of clot lysis) of standard and different test samples

The data are displayed with mean \pm S.E.M.

\begin{tabular}{ll}
\hline Test sample & \% clot Lysis \\
\hline Aqueous soluble fraction & $15.11 \pm 1.1$ \\
Ethyl acetate soluble fraction & $2.78 \pm 0.57$ \\
Chloroform soluble fraction & $12.41 \pm 0.59$ \\
Pet ether soluble fraction & $15.40 \pm 1.2$ \\
Streptokinase & $17.82 \pm 0.99$ \\
\hline
\end{tabular}

\section{Antimicrobial Screening:}

In this inspection, none of the organic fractions did not show any significant antimicrobial activity as compared to the standard ciprofloxacin and tetracycline.

\section{Evaluation of analgesic activity:}

The writhing count for each mouse was recorded and the average count for each group was calculated. The percentage inhibition of writhing was calculated with respect to the control. The higher the inhibition percentage of the group, the greater is the group's peripheral analgesic activity. The result was statistically evaluated, and the t-test and p-values were determined in comparison with Diclofenac sodium.

Table 4: Screening of analgesic activity and statistical evaluation

\begin{tabular}{lllll}
\hline Animal group & $\begin{array}{l}\text { Inhibition } \\
(\%)\end{array}$ & $\begin{array}{l}\text { t test } \\
\text { value }\end{array}$ & P value & Statistical significance \\
\hline Standard & $80.65 \pm 0.25$ & 25 & 0.0001 & Extremely statistically significant \\
Dose at $200 \mathrm{mg} / \mathrm{kg}$ & $61.29 \pm 0.11$ & 6.0083 & 0.0039 & Very statistically significant \\
Dose at $400 \mathrm{mg} / \mathrm{kg}$ & $66.13 \pm 0.29$ & 20.5 & 0.0001 & Extremely statistically significant \\
\hline
\end{tabular}

Statistical evaluation of the data confirmed that both doses showed significant peripheral analgesic activity with percent inhibition of writhing responses $61.29 \%(200 \mathrm{mg} / \mathrm{kg})$ and $66.13 \%(400 \mathrm{mg} / \mathrm{kg}$ ), respectively (Table 4). The results were expressed as means \pm S.E.M, and analyzed for statistical significance using t-test. $\mathrm{P}$ values $<0.05$ were considered significant.

\section{Evaluation of antidiarrheal activity:}

It has found that the methanolic extract of this plant exhibited statistically significant antidiarrheal activity at both $200 \mathrm{mg} / \mathrm{kg}$ and $400 \mathrm{mg} / \mathrm{kg}$ of doses at different time (after $1 \mathrm{hr}$, 2hr, 3hr and 4hr) (Table 5). 
Table 5: Screening of antidiarrheal activity

\begin{tabular}{ll}
\hline Animal group & Inhibition (\%) \\
Standard & $69.70 \pm 0.53$ \\
Dose at $200 \mathrm{mg} / \mathrm{kg}$ & $72.73 \pm 0.95$ \\
Dose at $400 \mathrm{mg} / \mathrm{kg}$ & $66.67 \pm 0.62$ \\
\hline
\end{tabular}

The results were expressed as means \pm S.E.M, and analyzed for statistical significance using $\mathrm{t}-$ test and $\mathrm{p}$-values, where $\mathrm{P}$ values $<0.05$ were considered significant.

\section{Evaluation of hypoglycemic activity:}

Although the methanolic extract of this plant has blood glucose lowering activity at both doses of $200 \mathrm{mg} / \mathrm{kg}$ and $400 \mathrm{mg} / \mathrm{kg}$ of body weight of mice at different time (after 30mins, $60 \mathrm{mins}$, 120 mins), but it was found not to be statistically significant.

\section{CONCLUSION}

All of the compounds isolated and elucidated from the methanolic extract of ethyl acetate soluble fraction of the whole plant of Hygrophila erecta (Burm.f.) Hochr. were first time reported. Biological screening of different organic fractions also demonstrated significant antioxidant and cytotoxic property. However, it expressed highest to moderate thrombolytic property, whilst also expressed statistically significant analgesic and antidiarrheal activity. Therefore, on the whole of its potential bioactivity, the plant material can be further being studied extensively to find out their unexplored efficacy, which could be a target compound for the development of new drug therapies.

\section{REFERENCES}

1. Khan I, Jan SA, Shinwari ZK, Ali M, Khan Y, Kumar T. Ethnobotany and medicinal uses of folklore medicinal plants belonging to family Acanthaceae: An updated review. MOJ biology and medicine. 2017; 1: 34-38.

2. Fongod AG, Modjenpa NB, Veranso MC. Ethnobotany of Acanthaceae in the Mount Cameroon region. Journal of Medicinal Plants Research. 2013 Oct 10; 7: 2859-2866.

3. Chowdhury A, Das AP. Hygrophila erecta (NL Burman) Hochreutiner [Acanthaceae]a new record of occurrence for West Bengal, India. Pleione. 2014; 8: 207-209.

4. VanWagenen BC, Larsen R, Cardellina JH, Randazzo D, Lidert ZC, Swithenbank C. Ulosantoin, a potent insecticide from the sponge Ulosa ruetzleri. The Journal of Organic Chemistry. 1993; 58: 335-337.

5. Brand-Williams W, Cuvelier M, Berset C. Use of a free radical method to evaluate antioxidant activity. LWT- Food Science and Technology. 1995; 28: 25-30.

6. Meyer BN, Ferrigni NR, Putnam JE, Jacobsen LB, Nichols DE, McLaughlin JL. Brine Shrimp: a convenient general bioassay for active plant constituents. Journal of Medicinal Plant Research. 1982; 45:31-34.

7. Prasad S, Kashyap RS, Deopujari JY, Purohit HJ, Taori GM, Daginawala HF. 
Development of an in vitro model to study clot lysis activity of thrombolytic drugs. Thrombosis Journal. 2006; 4: 9-12.

8. Bayer AW, Kirby WM, Sherris JC, Turck M. Antibiotic susceptibility testing by a standardized single disc method. American Journal of Clinical Pathology. 1966; 45: 493-496.

9. Whittle BA. The use of changes in capillary permeability in mice to distinguish between narcotic and nonnarcotic analgesics. British journal of pharmacology and chemotherapy. 1964; 22: 246-253.

10. Shoba FG, Thomas M. Study of antidiarrhoeal activity of four medicinal plants in castor-oil induced diarrhoea. Journal of ethnopharmacology. 2001; 76: 73-76.

11. Joy KL, Kuttan R. Anti-diabetic activity of Picrorrhiza kurroa extract. Journal of Ethnopharmacology. 1999; 67: 143-148.

12. Zhang X, Zhang WZ, Shi LL, Guo CX, Zhang LL, Lu XB. Electronic Supplementary Material (ESI) for Chemical Communications. The Royal Society of Chemistry. 2012; 8: 6292-6294.

13. Bylka W. E-and Z-p-methoxycinnamic acid from Aquilegia vulgaris. Acta poloniae pharmaceutica. 2004; 61: 307-308.

14. Knothe G. ${ }^{1}$ H- NMR Spectroscopy of Fatty Acids and Their Derivatives - Nonconjugated double bonds. Journal of the American Oil Chemists' Society. 2006; 90: 835-840.

15. Jahan M, Bao Q, Yang JX, Loh KP. Structure-directing role of graphene in the synthesis of metal- organic framework nanowire. Journal of the American Chemical Society. 2010; 132: 14487-14495.

16. Pateh UU, Haruna AK, Garba M, Iliya I, Sule IM, Abubakar MS, Ambi AA. Isolation of stigmasterol, $\beta$-sitosterol and 2-hydroxyhexadecanoic acid methyl ester from the rhizomes of Stylochiton lancifolius Pyer and Kotchy (Araceae). Nigerian Journal of Pharmaceutical Sciences. 2009; 8: 19-25.

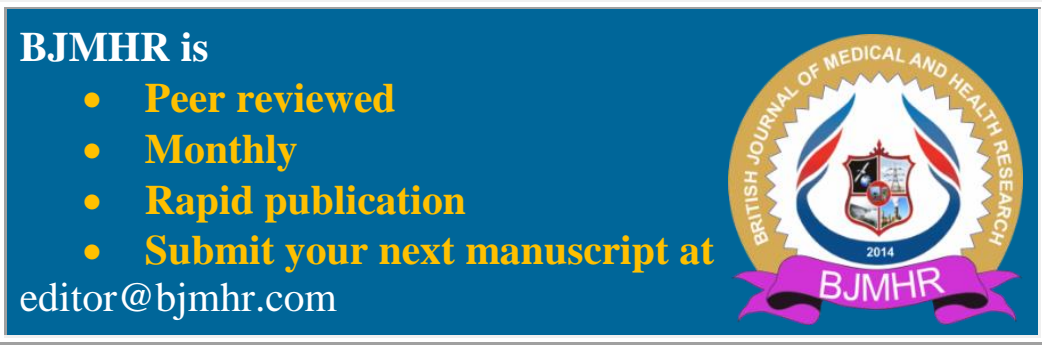

